\title{
الإجماع السكوتي
}

الباح/ ماجد بن خليفة السلهي
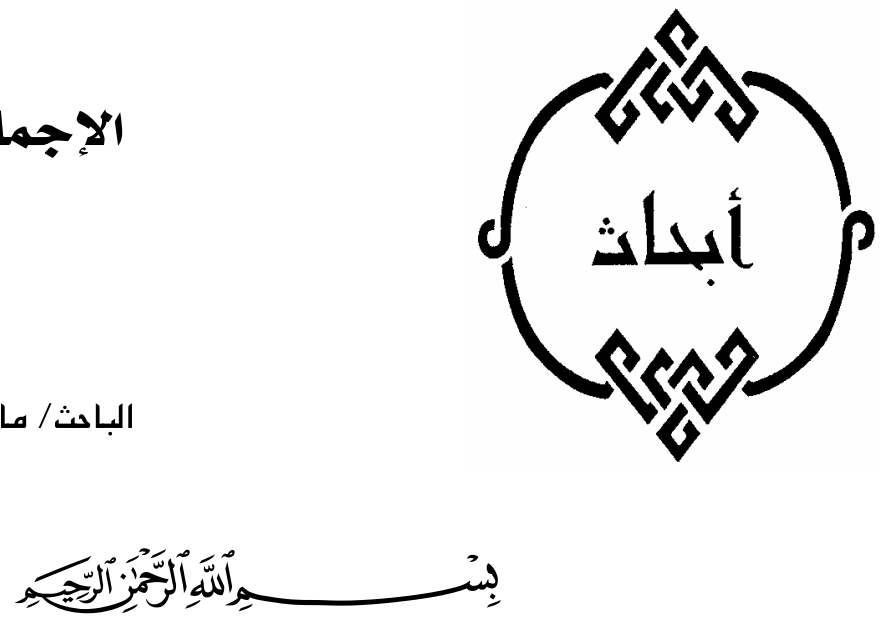

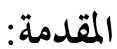

إن الحمد الله، نحمده و نستعينه، و نستغفره ونستهديه، ونعوذ بالله من شرور أنفسنا

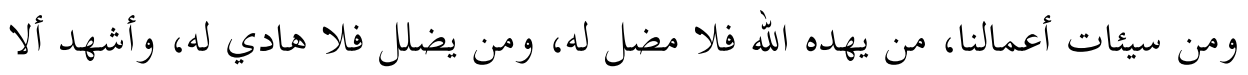

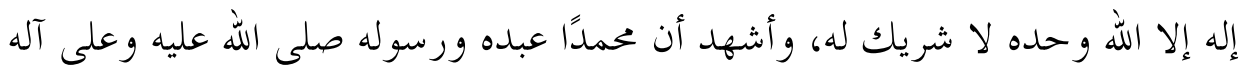

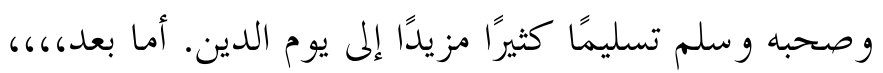

فإن من أفضل ما تقضى فيه الأوقات، وتصرف فيه الساعات طلب العلم الشرعي؛ لأنه حياة القلوب، ونور الصدور، يبدد الله به عن النفس ظلمات الجهل و الهوى،

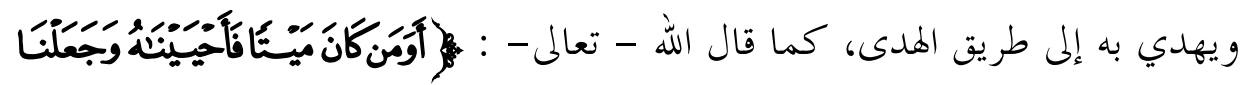

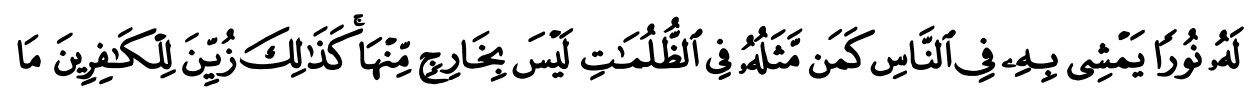

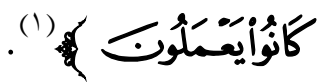
وإن من توفيق الله لعبده أن يجعله ممن يسلك هذا الطريق - طريق العلم الشرعي - 
علم الكتاب والسنة وما يخدمهما من العلوم الموصلة للعلم هما، وإن من أجلّ العلوم

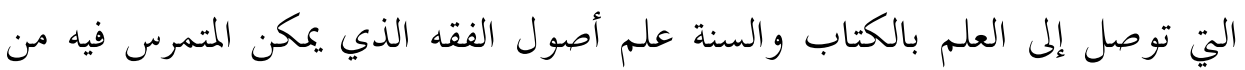
النظر الصحيح في الأدلة الشرعية، ومقاصدها، وقواعد الدين الكلية، واستباط الأحكام منها بإتقان وبصيرة.

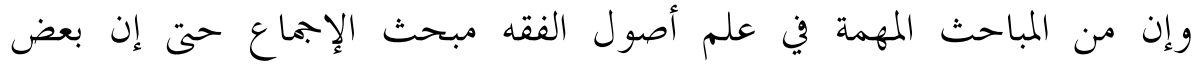
الأصوليين عده من أقوى الأدلة.

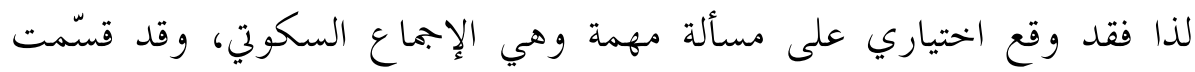
البحث إلى مقدمة وثلاثة مطالب وخاتمة: المطلب الأول: في تعريف الإجماع لغة واصطلاحًا.

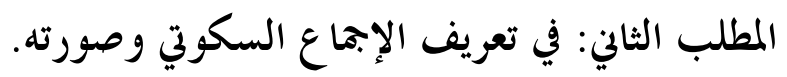
المطلب الثالث: في أقوال العلماء والمناقشة والثرجيح.

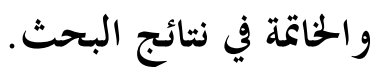
وقد سلكت فيه المنهج العلمي من حيث عزو الآيات، وتخريج الأحاديث، وتوثيق

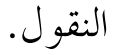

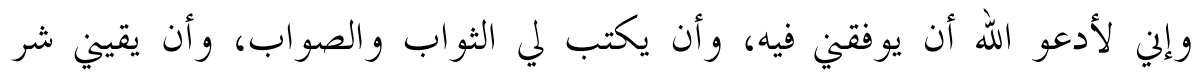

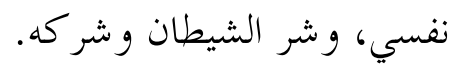

وصلى الله على نبينا محمد وعلى آله وصحبه أجمعين والحمد لله رب العالمين. 


\section{الهطلب الأول \\ في تعريف الإجماع لغت واصطاً}

الإجماع في اللغة: يطلق ويراد به معان كثيرة، أشهرها: الاتفاق، يقال: أجمع القوم على كذا، إذا اتفقوا عليه.

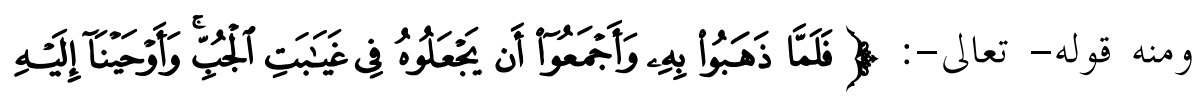

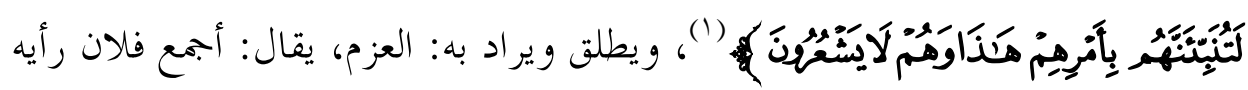

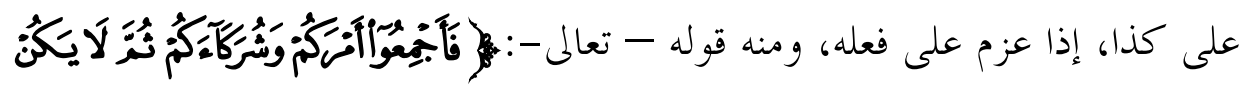

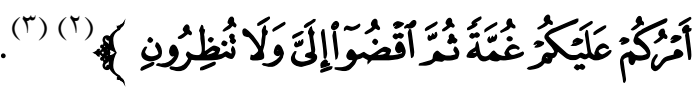
وفي الاصطلاح: تعددت تعريفات الأصوليين له، وذلك راجعٌ إلى اختلافهم في اشتر اط شروط يروها في الإجماع، فمن تعريفاقهم: أ- قال ابن العربي: "الإجماع: أن يتفق أهل العصر بأجعهم عامتهم وخحاصتهم

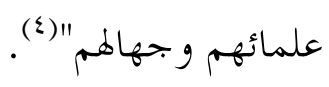
و بالنظر لهذا التعريف بجد أنه يرى دخول العوام في الإجماع.

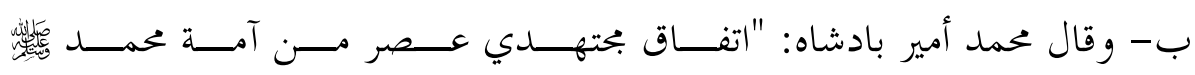
على أمر شرعي" (0) - (ن)

$$
\text { (Y) سورة يوسف، آية (10). (Y) سورة يونس، آية (V) (Y). }
$$

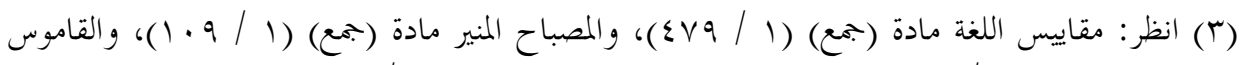

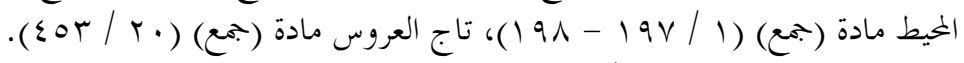

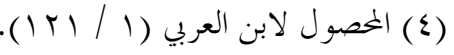

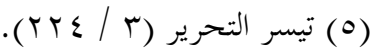


جـ-- وقال المرداوي(1): "اتفاق بحتهدي الأمة في عصر على أمر ولو فعلاً بعد

\section{و بالنظر في التعريفين الآخرين يمكن أن نستنتج أموراً هي:}

1 - اتفقا على أنّ الإجماع خاص باتفاق المجتهدين ولا يشار كهم فيه العو ام. r - أن يكون الإجماع واقعاً على أمر شرعي، ويخرج بذلك ما لو اتفقوا على أمرٍ

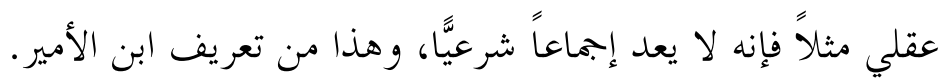

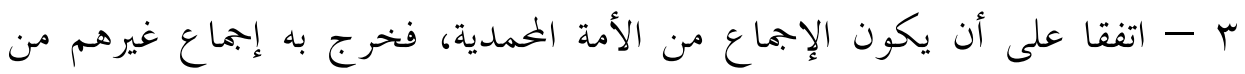
الأمم؛ لأن العصمة إنما ثبتت لهذه الأمة.

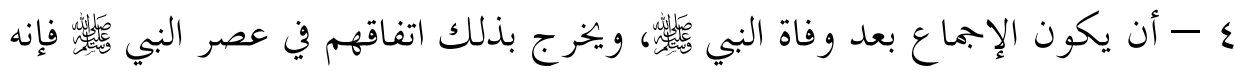
لا يعد إجماعاً. و كلا التعريفين صحيح.

(1) هو: علي بن سليمان بن أحمد بن محمد المرداوي ثم الدمشقي، فقيه أصولي حنبلي، ولد سنة (هIV)

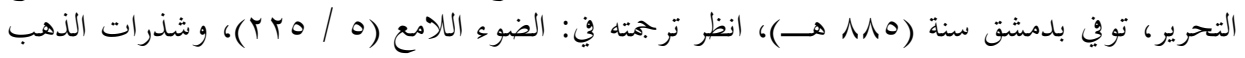




\section{المطلب الثاني \\ في تعريف الإجماع السكوتي وصورته}

تنوعت عبارات الأصوليين في تعريف الإجماع السكوتي:

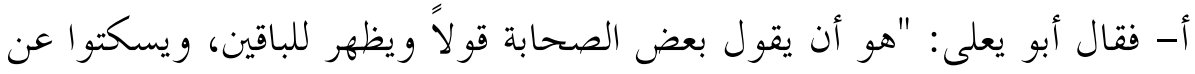

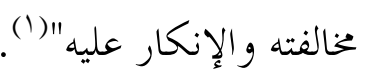

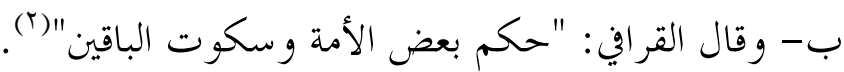

جـ- وقال الطوفي: "إذا اشتهر في الصحابة قول بعضهم التكليفي و لم ينكر" "(").

د- وقال ابن أمير الحاج (๕): "هو ما كان بقول البعض وسكوت الباقين"(0).

و بالنظر لتعريف أبي يعلى والطوفي بجد: أهما قد قصرا الإجماع السكوتي على عصر الصحابة فقط، أما تعريف القرافي وابن أمير الحاج فجعلاه شاملاً لعصر الصحابة وغيرهم، كما اتفق أبو يعلى و الطوفي وابن الأمير على قصره على القول دون الفعل. وصورة المسألة: أن يقول واحد من أهل الحل والعقد في مسألة بقول، وينتشر في

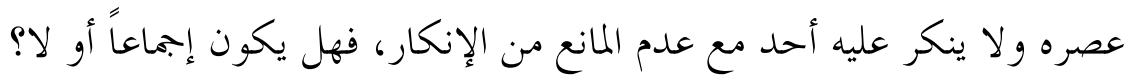
***

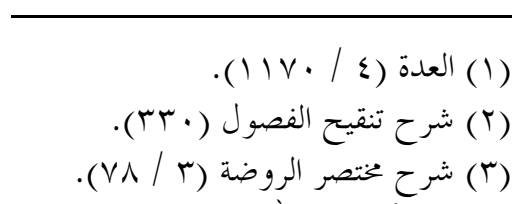

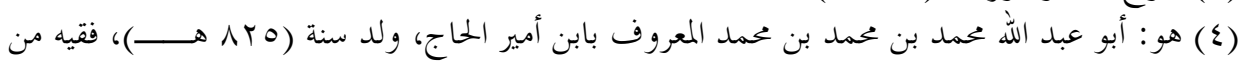

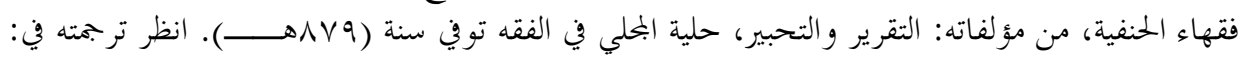
الضوء اللامع (9/9 / . (Y). (0) انظر: التقرير والتحبير (r / • •ـ (). 


\section{المطلب الثالث}

\section{آراء الأصوليين في الإجماع السكوتي}

اتفق العلماء على أن الإجماع السكوتي إذا لم يكن في حكم تكليفي فليس بإجماع

ولا حجة، لأن الإجماع أمر ديني، وما ليس تكليفاً ليس دينيًا، بل دنيوي (1).

كما اتفقوا على اشتراط اشتهار القول، فلو لم يشتهر لم يدل سكوةهم على الموافقة،

وألحق بعضهم بالاشتهار قول البعض فيما تعم به البلوى وسكوت الباقين (r).

وإذا كان الإجماع في تكليف وانتشر فيهم فسكتوا، فلا يخلوا من ثلاث حالات: * الأولى: أن يعلم من قرينة حال الساكت أنه راضٍ بذلك، فهو إجماع قولاً و احداً.

* الثانية: أن يعلم من قرينة أنه ساخط غير راضٍ بذلك، فليس بإجماع قولاً واحداً. * الثالثة: ألاّ يُعلم منه رضى ولا سخط، فهذه التي وقع فيها الخلاف (广) على أقوال، أقتصر على أشهرها:

* القول الأول: أنه حجة وإجماع، وبه قال الإمام أحمد بن حنبل(๕)، وأكثر أصحاب أبي حنيفة(0) و وبعض الشافعية(7).

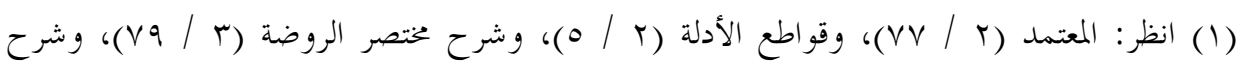

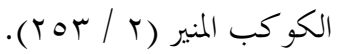

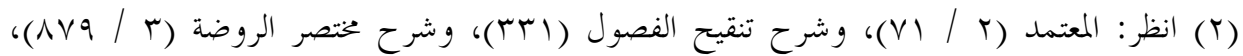

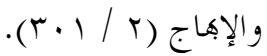

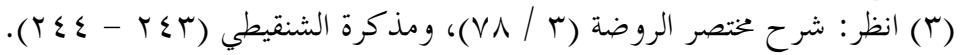

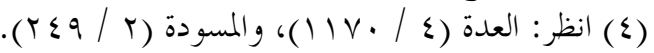

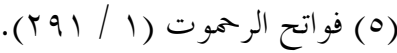

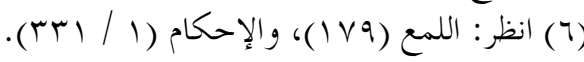




\section{واستدلوا على ذلك بأدلة منها:}

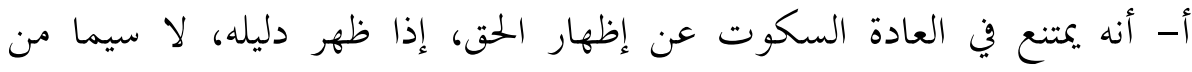

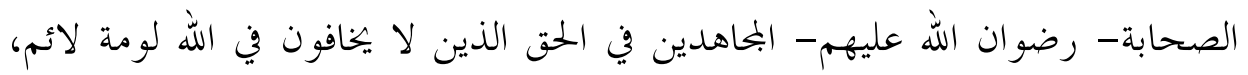

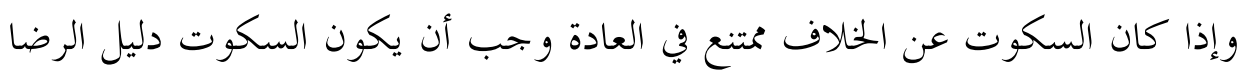

عادة، فيكون السكوت منهم إجماعًاً (1).

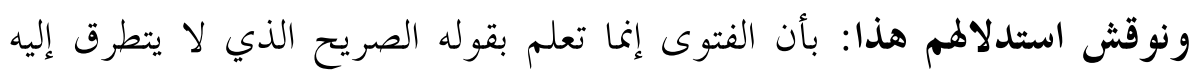

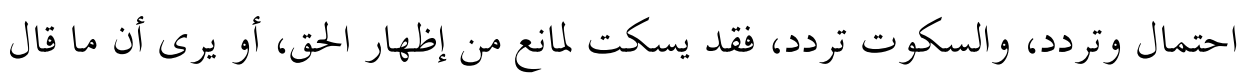

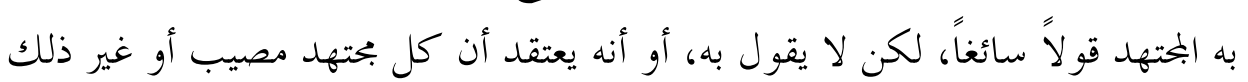

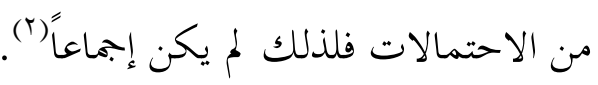

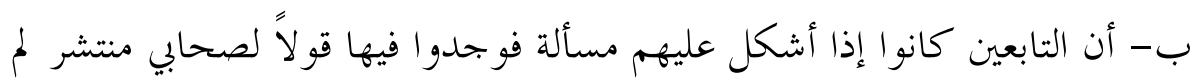

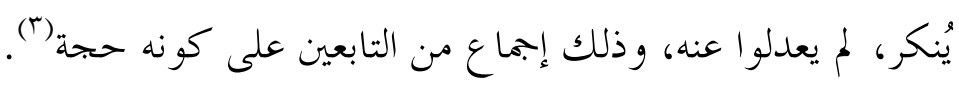

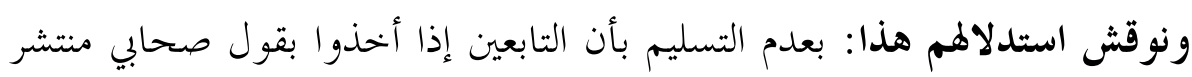

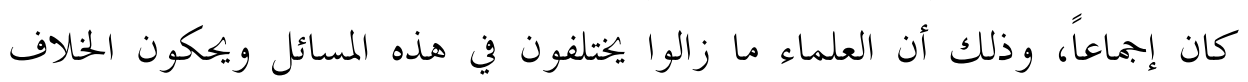
فيها (5) (2)

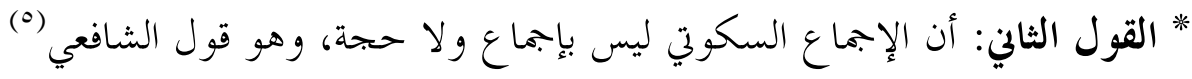

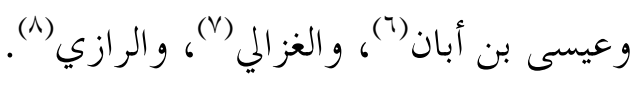

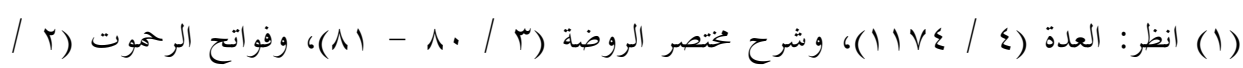

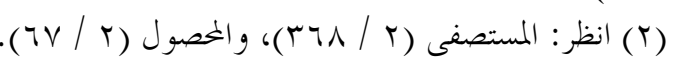

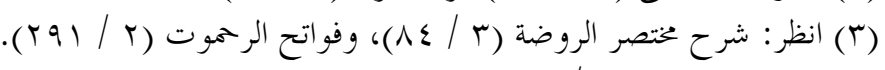

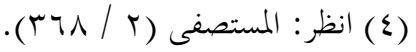

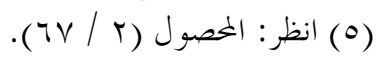

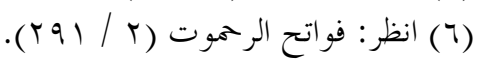

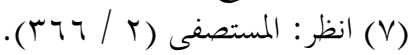

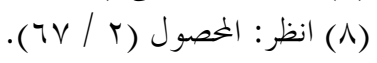


واستدلوا على ذلك بقولهم: إن سكوت من سكت يحتمل أن يكون سكت؛ لأنه مو افق، ويحتمل أنه لم يجتهل بعد في حكم الواقعة، ويحتمل أنه اجتهد لكنه لم يؤده

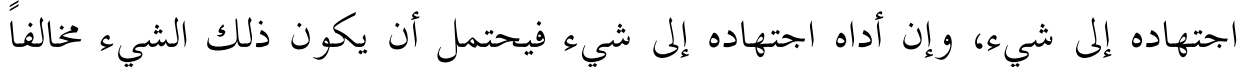

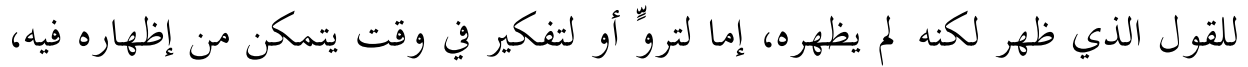
وإما لاعتقاده أن القائل بذلك بحتهد و لم يرد الإنكار عليه لاعتقاده أن كل بحتهد مصيب، أو لأنه سكت خشية ومهابة، أو خوف ثوران فتنة، كما نقل عن ابن عباس

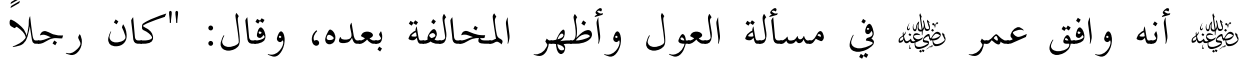
مهيباً"، و إما لظنه أن غيره كفاه مؤنة الإنكار وهو فئ مخطئ فيه (1).

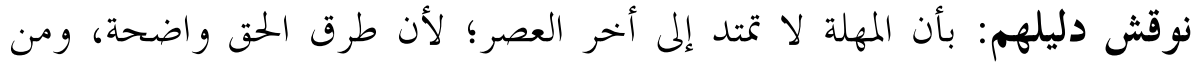
نظر فيها من أهل الاجتهاد فلا بد أن يصل إلى الحق، وقولهم يحتمل أن يكونوا

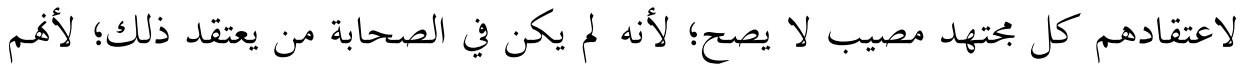

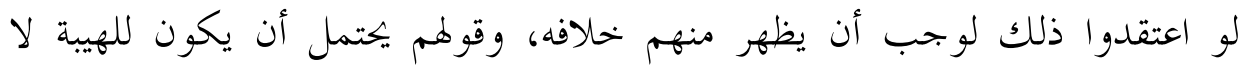

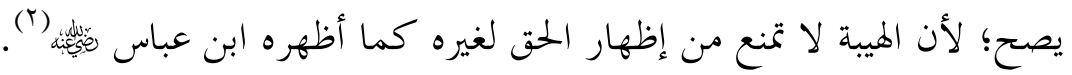

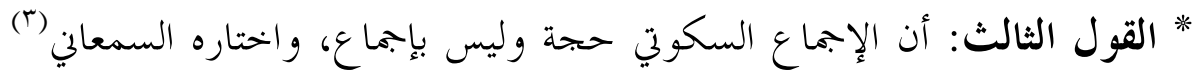
وأبو هاشم (\&)، وأبو بكر الصيرفي (o)

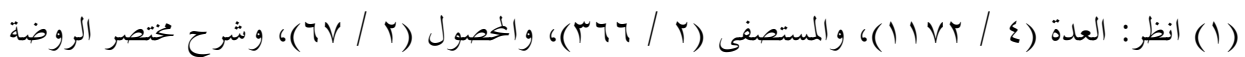

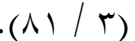

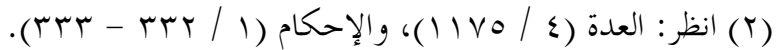

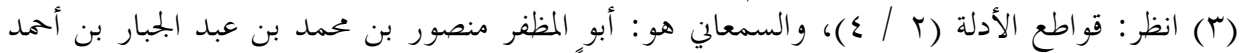

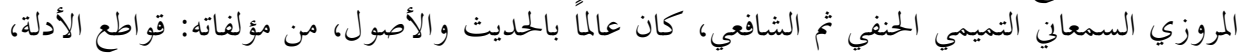

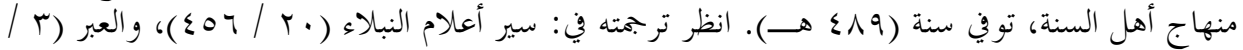

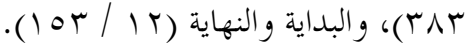

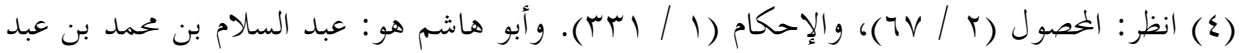

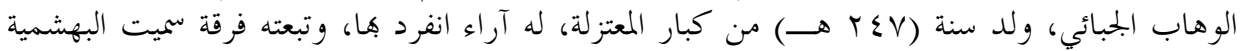

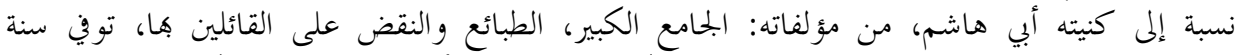

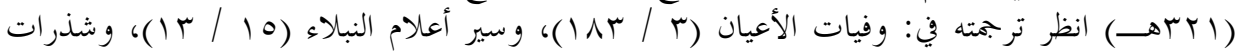

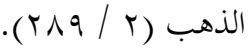
(0) انظر: قواطع الأدلة (ץ / ع)، والصيرفي هو: أبو بكر محمد بن عبد الله الصيرفي، أحد علماء= 


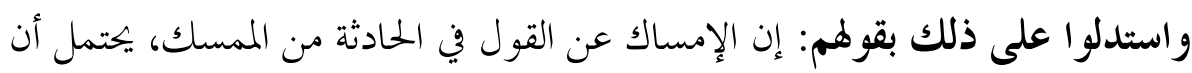

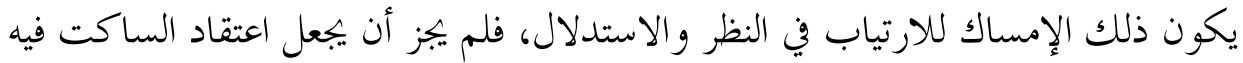

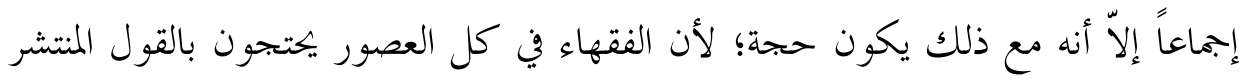

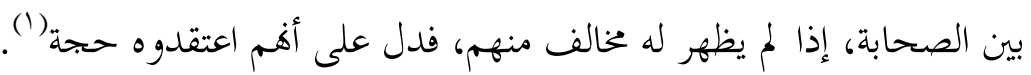

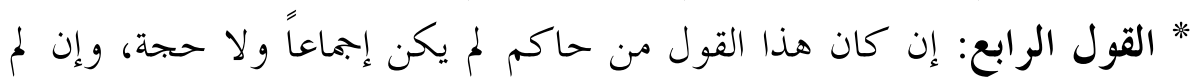

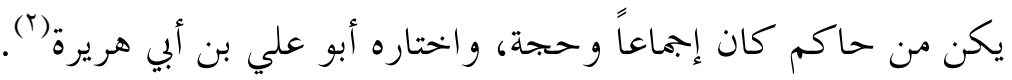

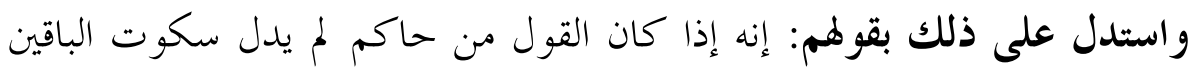

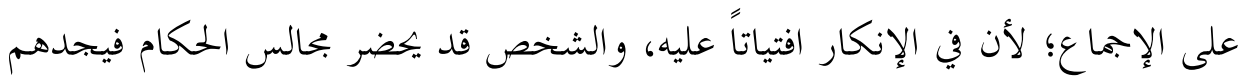

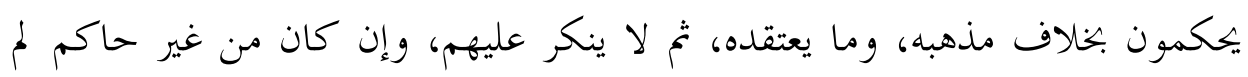

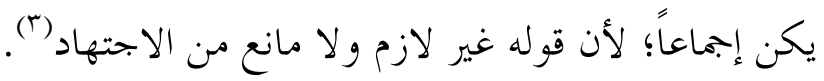

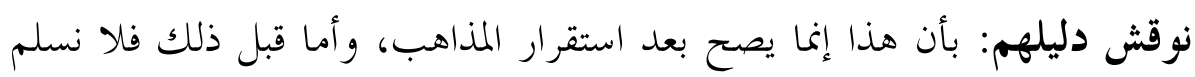

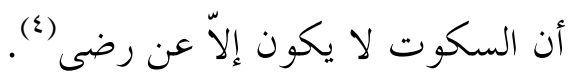

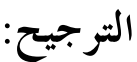

بعد عرض الأدلة والمناقشات يتبين أن الراجح - و والله أعلم - هو القول الثالث

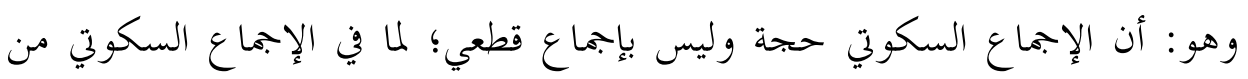

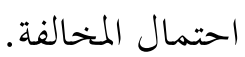

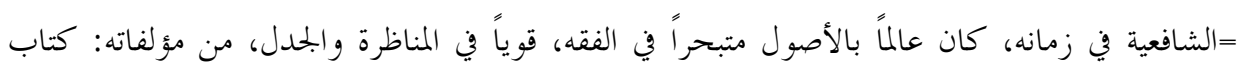

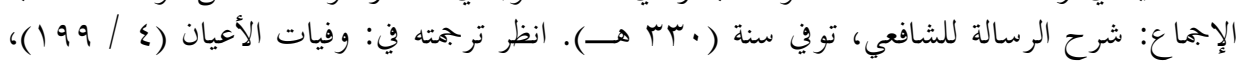

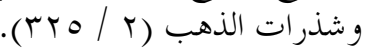

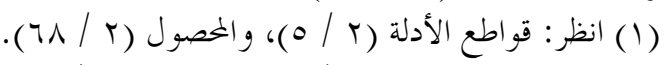

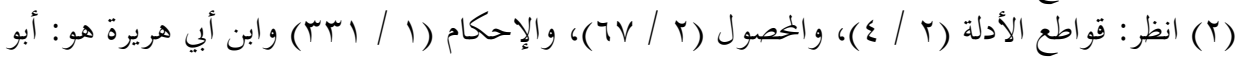

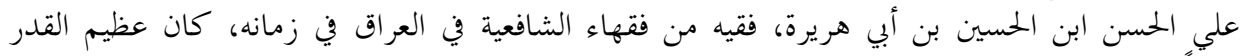

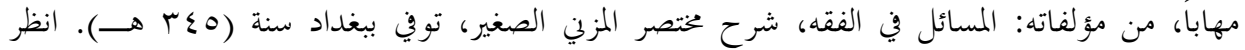

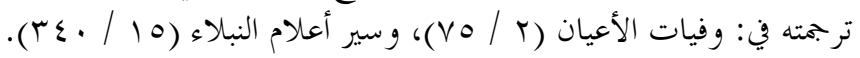

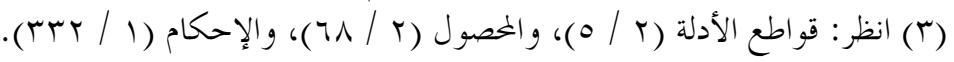

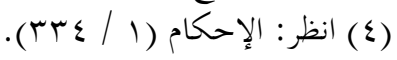




\section{الخاتهمت}

وفي الختام أحمد الله وِّيَلْ على ما منّ به على من إكمال هذا البحث وإتمامه، وقد توصلت إلى نتائج من أهمها:

- أن الإجماع هو ما أجمع عليه علماء الأمة من أهل الحل و العقد. r- أن الإجماع منه ما هو صريح ومنه ما هو سكوتي.

ب- صورة الإجماع السكوتي: أن يقول واحد من أهل الحل و العقد في مسألة بقول، وينتشر في عصره ولا ينكر عليه أحد مع عدم المانع من الإنكار.

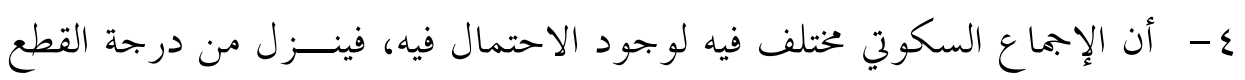

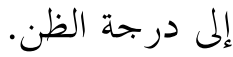

ه- أن الإجماع السكوتي مع كونه ظنيا إلا أنه يقدم على غيره من الأدلة حال التعارض كالقياس مثلاً.

هذا وأسأل الله أن يجعل خير أعمالنا خواتيمها، وخير أيامنا يوم نلقاه إنه ولي ذلك آلك

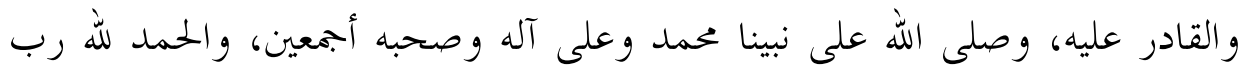

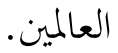




\section{ثبت المصاد روالمراجع}

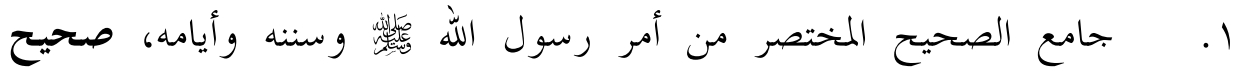
البخاري للإمام أبي عبد الله البخاري (†ه بهــ) تحقيق: مصطفى ديب البغا، طبع دار ابن كثير . - مات

r. الابتهاج في شرح المنهاج لعلي بن عبد الكافي السبكي (ت־هVهـ)، وولده تاج الدين السبكي (ت IVIهـ)، طبع دار الكتب العلمية، علق عليه: محمود أمية السيد، ط الأولى.

r. الإحكام في أصول الأحكام لسيف الدين الآمدي (ت آبآهـ)، طبع دار الصميمي، علق عليها الشيخ عبد الرزاق عفيفي ط الأولى.

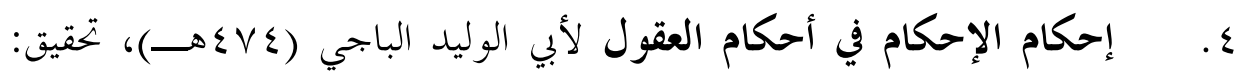
عبد البميد التركي ط الثانية سنة ه إ اهــ، دار الغرب الإسلامي. ه. الرسالة لمحمد بن إدريس الشافعي (تع • بهــ)، تحقيق: أحمد شاكر طبع دار التراث ط الثانية.

7. آراء المعتزلة الأصولية لعلي بن سعد الضويهي طبع مكتبة الرشد، الثالثة.

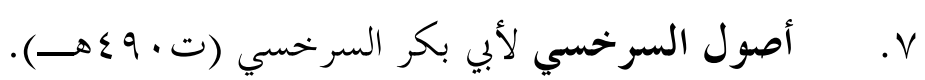

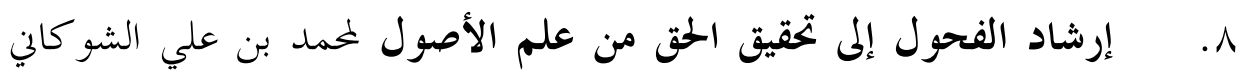

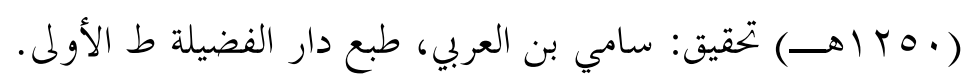

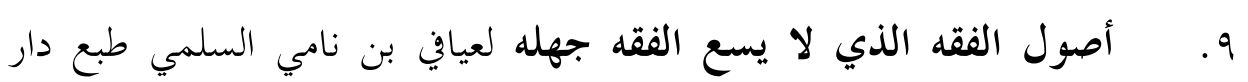
التدمرية ط الثانية. 
•. . الأصول من علم الاصول للشيخ محمد بن صالح العثيمين طبع دار طيبة ط الثانية.

11. أصول مذهب الإمام أحد لعبد الخحسن التركي طبع مؤسسة الرسالة ط

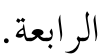

T ا. إعلام الموقعين عن رب العالمين لشمس الدين بن قيم الجوزية (ت اOVVه))،

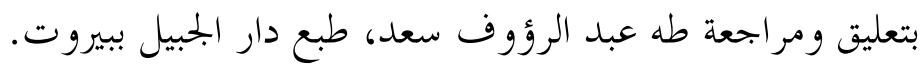

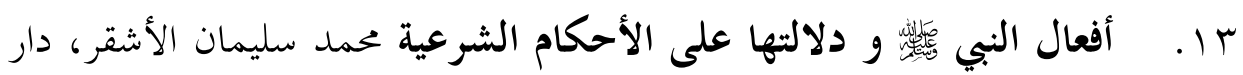

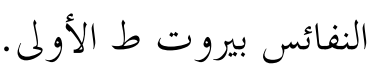
ع ا. البحر الخيط في أصول الفقه لبدر الدين الزركشي (تع ولهـهـ)، طبع دار الكتبي، بتحقيق لجنة من علماء الأزهر، ط الثالثة.

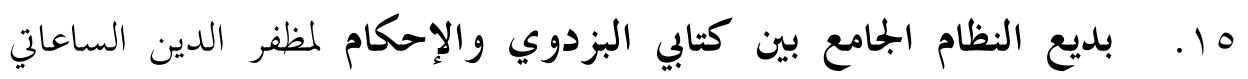

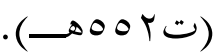

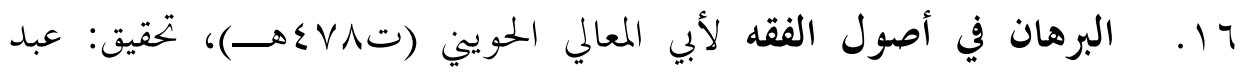
العظيم محمود الدين، طبع دار الوفاء، ط الرابعة.

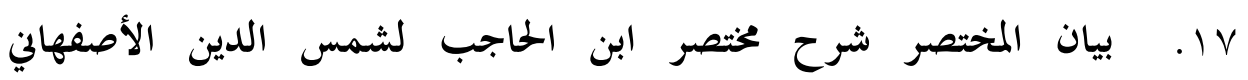
(ت9 § \هـ)، طبع مركز إحياء التراث الإسلامي، تحقيق: محمد مظهر بقان.

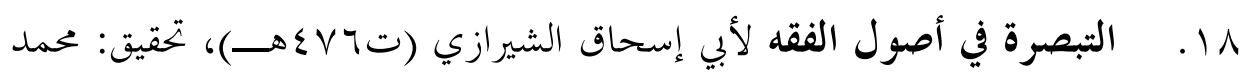

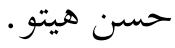

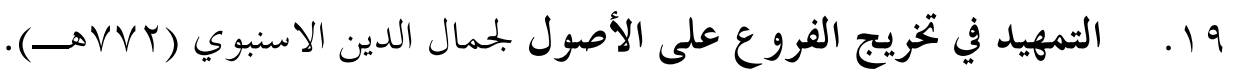

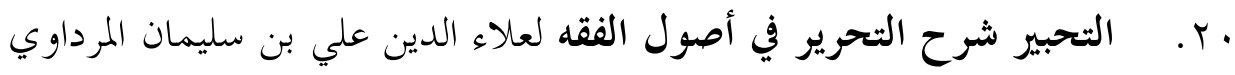

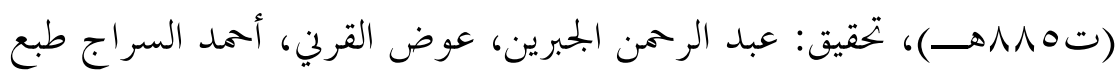


مكتبة الرشد ط الأولى، تحقيق: محمد حسن محمد، طبع دار الكتب العلمية

$$
\text { اب ب التيروت، ط الأولى. }
$$

r r . ت تشنيف المسامع بجمع الجوامع لبدر الدين الزركشي تحقيق: د عبد الله ربيع، ود. سيد عبد العزيز، طبع مؤسسة قرطبة و المكتبة المكية ط الثانية.

rr. تيسير التحرير على كتاب التحرير لمحد أمين المعروف بأمير بادشاه

$$
\cdot(\longrightarrow 9 \wedge \vee ت)
$$

ع . . حاشية العطار على شرح الخلى على بمع الجوامع لحسن العطار

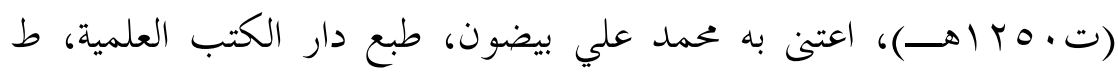

$$
\text { الأولى. }
$$

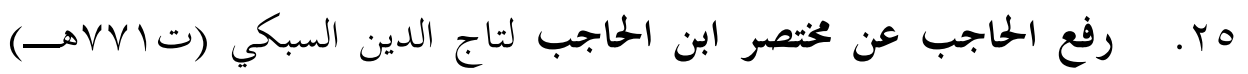

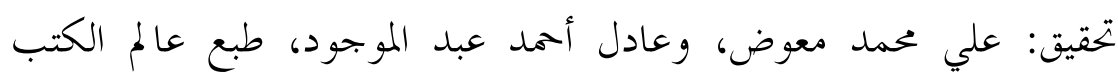

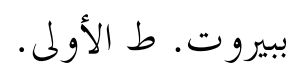

Tr. روضة الناظر وجنة المناظر لأبي محمد عبد الله بن احمد بن قدامة (ت . ب7هــ)، طبع المكتبة المكية و......الريان، ط الثانية.

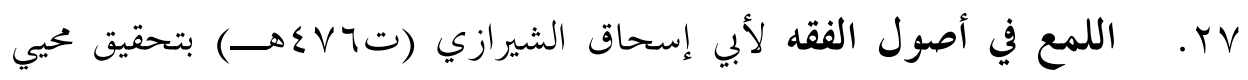
الدين ديب متو، يوسف علي بديوي، طبع دار ابن كثير، ط الثالثة.

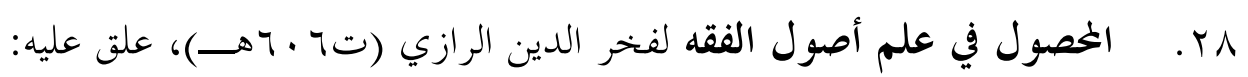
محمد عبد القادر عطا، طبع دار الكتب العلمية ط الأولى.

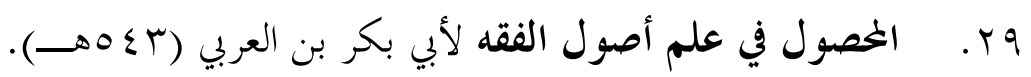


•r. المستصفى من علم الأصول لأبي حامد محمد بن محمد الغزالي (ته.0.0ـ)، تحقيق: حمزة زهير حافظ.

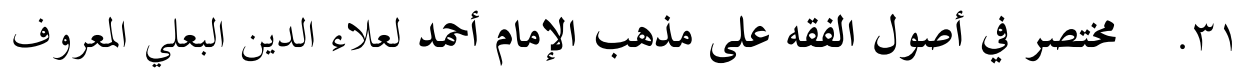

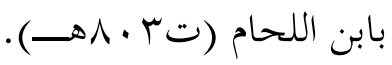

r.r. مذكرة في أصول الفقه على روضة النه الناظر محمد الأمين الشنقيطي (ت و جr اهــ)، إشراف: بكر عبد الإله أبو زيد، طبع دار عالم الفوائد.

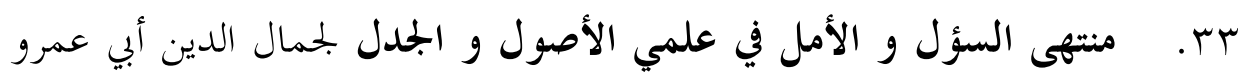
ابن الحاجب (7 ـآهـ)، طبع دار الكتب العلمية بيروت، ط الأولى.

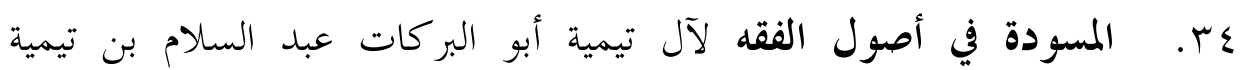

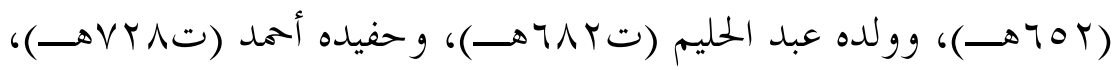
تحقيق: أحمد الندوي، طبع دار الفضيلة ط الأولى.

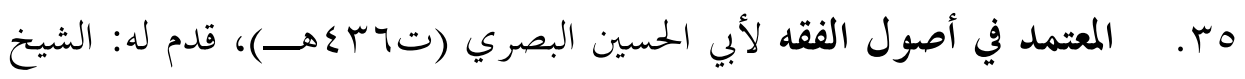
خليل الميس، دار الكتب العلمية ببيروت.

بr. مفتاح الوصول إلى بناء الفروع على الأصول للثريف التلمساني

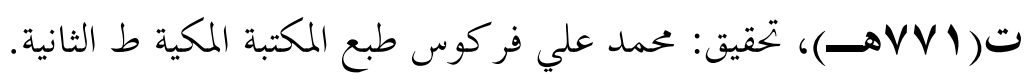

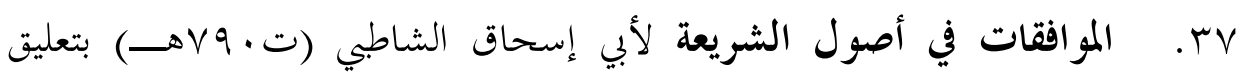
الشيخ عبد الله دراز طبع دار الكتب العلمية.

مبـ. نثر الورود على مراقي السعود للشيخ محمد الأمين الشنقيطي (ت ج و ا اهـ)، تحقيق: علي محمد العمر ان طبع دار عالم الفو ائد ط الأولى. 
وب. نفائس الأصول في شرح الخصول لشهاب الدين القرافي (تم^؟جهـ)، تحقيق: عادل أحمد عبد الموجود، وعلي محمد معوض، نشر مكتبة الباز. ط لط الثانية.

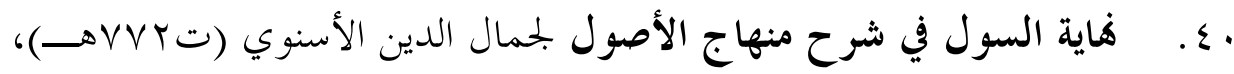
تحقيق: محمد شعبان إسماعيل، طبع دار ابن حزم، ط الأولى. اءـ. العدة في أصول الفقه لأبي يعلى البغدادي الحنبلي (تمهـهـ)، تحقيق: أحمد علي المبار كي، ط الثانية.

بـ . فواتح الرحمت بشرح مسلم الثبوت لمحمد بن نظام الدين الأنصاري

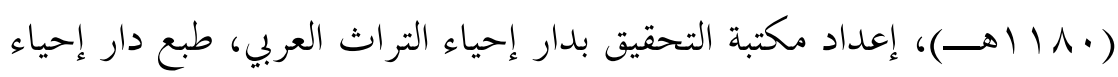

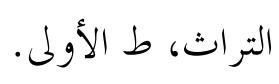

بــ. قواطع الأدلة في الأصول لأبي المظفر السمعاني، تحقيق: محمد حسن الشافعي، طبع دار الكتب العلمية، ط الأولى.

§ء. شرح تنقيح الفصول في اختصار الخصول لشهاب الدين القرامي

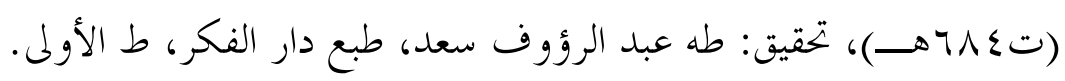

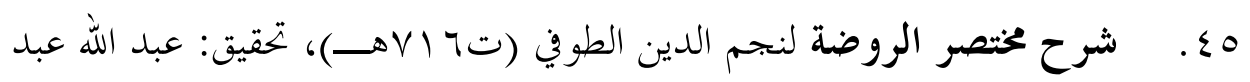
المحسن التركي، طبع مؤسسة الرسالة، ط الثانية.

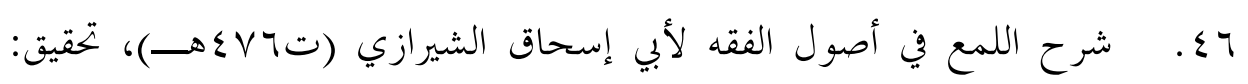
علي عبد العزيز العميريني، طبع دار البخاري.

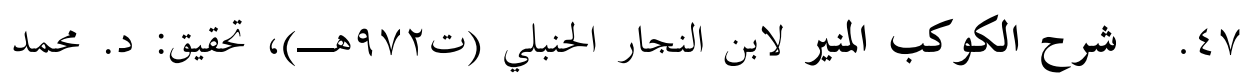
الزحيلي، ود. نــزيه حماد، طبع مكتبة العبيكان، ط الثانية. 


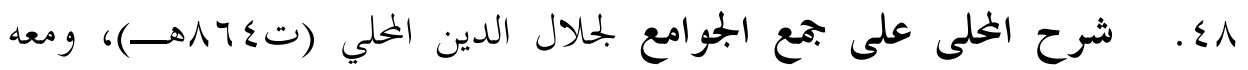
حاشية البناني (ت1911 1 1هــ)، تقرير عبد الرحمن الشربيني، طبع دار الفكر. 9ء. شرح المنهاج للبيضاوي في علم الأصول لشمس الدين الأصفهاني

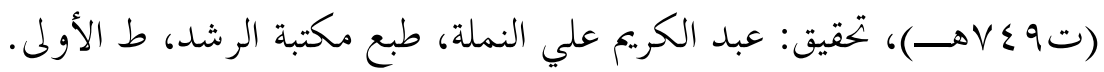
•. . شرح العضد على مختصر المنتهي الأصول لعضد الدين الزيجي (ت7ه Vهـ) وهامشه حاشية سعد الدين التفتازاني (ت (19هـ)، وحاشية الشريف الجرجاني (ت ب ا مهــ)، طبع دار الكتب العلمية. *** 